\section{Educational Testing}

Fan $\mathrm{Wu}^{1}$ and Rik Carl D'Amato ${ }^{2}$

${ }^{1}$ Outcomes Management, The Harris Center for Mental Health and IDD, Houston, TX, USA

${ }^{2}$ School of Psychology, The Chicago School of Professional Psycology, Chicago, IL, USA

\section{Synonyms}

Academic skills

\section{Definition}

Education can be defined as learning knowledge and skills after receiving specialized training, such as teaching, tutoring, or advising. Testing can be viewed as a process or tool used to evaluate a person's knowledge, skills, or performance in a specialized area. Educational testing is the evaluation of students' academic abilities to determine current levels of academic achievement, such as reading, mathematics, or vocabulary. In our current age of accountability, educational testing is often used as an inappropriate indicator of quality instruction. Such a score is not useful because learning is multifaceted and cannot be limited to a single number. However, educational testing should be a critical component of the learning process within the education enterprise.

\section{Cross-References}

- Academic Competency

- Basic Achievement

- Reading

- Vocabulary

\section{References and Readings}

D’Amato, R. C., Crepeau-Hobson, F. C., Huang, L. V., \& Geil, M. (2005). Ecological neuropsychology: An alternative to the deficit model for conceptualizing and serving students with learning disabilities. Neuropsychology Review, 15(2), 97-103.

Witsken, D., Stoeckel, A., \& D'Amato, R. C. (2008). Leading educational change using a neuropsychological response-to-intervention approach: Linking our past, present, and future. Psychology in the Schools, 45(9), 781-798. 